\title{
Protein kinase C-mediated necrosis-apoptosis switch of cortical neurons by conditioned medium factors secreted under the serum-free stress
}

\author{
R Fujita ${ }^{1}$ and $\mathrm{H} \mathrm{Ueda}^{*, 1}$ \\ 1 Division of Molecular Pharmacology and Neuroscience, Nagasaki University \\ Graduate School of Biomedical Sciences, Nagasaki, Japan \\ * Corresponding author: H Ueda, Division of Molecular Pharmacology and \\ Neuroscience, Nagasaki University Graduate School of Biomedical Sciences, \\ Nagasaki, 1-14 Bunkyo-machi, Nagasaki 852-8521, Japan. Tel: +81-95-844- \\ 4277; Fax: +81-95-844-4248; E-mail: ueda@net.nagasaki-u.ac.jp
}

Received 8.5.02; revised 24.1.03; accepted 11.2.03

Edited by Y. Kuchimo

\begin{abstract}
Cortical neurons die in necrosis in the low-density (LD) culture, and in apoptosis in the high-density (HD) culture under the serum-free condition without any supplements. The neuronal death in LD culture was delayed by conditioned medium (CM) factors prepared from the HD culture. The CM switched the cell death mode from necrosis to apoptosis, characterized by various cell death markers and transmission electron microscopy. The $\mathrm{CM}$ inhibited the rapid decrease in cellular ATP levels and $\left[^{3} \mathrm{H}\right]-2$-deoxy glucose $\left(\left[{ }^{3} \mathrm{H}\right]-2-\mathrm{DG}\right)$ uptake in the LD culture. Inhibitors of phospholipase $C$ and protein kinase $\mathrm{C}$ effectively abolished the CM-induced elevation of survival activity, $\left[{ }^{3} \mathrm{H}\right]-2-\mathrm{DG}$ uptake and ATP levels, and necrosis-apoptosis switch. All these results suggest that $\mathrm{CM}$ caused the cell death mode switch from necrosis to apoptosis through phospholipase $\mathrm{C}$ - and protein kinase C-mediated mechanisms.

Cell Death and Differentiation (2003) 10, 782-790. doi:10.1038/ sj.cdd. 4401239
\end{abstract}

Keywords: necrosis; apoptosis; 2-deoxy glucose uptake; protein kinase $\mathrm{C}$; electron microscopy

Abbreviations: LD, low density; HD, high density; CM, conditioned medium factors; TEM, transmission electron microscopy; PLC, phospholipase C; TK, tyrosine kinase; PKC, protein kinase C; cyto $c$, cytochrome $c$; $\left[{ }^{3} \mathrm{H}\right]$-2-DG, $\left[{ }^{3} \mathrm{H}\right]-2$-deoxy glucose; WST8, 2-(2-methoxy-4-nitrophenyl)-3-(4-nitrophenyl)-5-(2, 4-disulfophenyl)-2H-tetrazolium monosodium salt; $\mathrm{LDH}$, lactate dehydrogenase; FITC, fluorescein isothiocyanate; TUNEL, terminal deoxunucleotidyl transferase-mediated dUTP nick end labeled; $\mathrm{PI}$, propidium iodide; PBS, phosphate-buffered saline; PFA, paraformaldehyde.

\section{Introduction}

Following ischemic stress of the brain, traumatic neuronal injury because of necrosis occurs in the ischemic core, while apoptosis occurs several days later at the region surrounding the core, called penumbra. ${ }^{1-5}$ If this pathological switch from necrosis to apoptosis has a significant role for the selfprotection of postmitotic brain, apoptosis is presumed to cease the propagation of necrotic neuronal death. However, it was difficult to reproduce this mechanism in the experimental culture system, since chemically induced necrosis was generally hard to be protected or switched to apoptosis by several treatments. ${ }^{6,7}$ On the other hand, the low-glucose and anoxia treatment is widely used as an ischemic stress model in the culture of neurons. ${ }^{8}$ However, as this model induces both necrotic and apoptotic features, it is hard to discuss the cell death mode switch.

We have recently characterized the death of cultured cortical neurons in the serum-free condition without any supplements. Under this condition, most neurons rapidly died in necrosis without apoptotic features. ${ }^{9}$ When the cell density was raised five-fold, however, the cell death was delayed and the death mode was switched to apoptosis without necrotic features. For the molecular basis of mechanism of this cell death mode switch, there are two possibilities including the contribution of cell-cell contacts and soluble factors secreted in the conditioned medium (CM). Here, we attempted to demonstrate the presence of soluble factors to induce such a cell death mode switch.

\section{Results}

\section{CM factors-induced survival of cortical neurons}

Under serum-free conditions, the survival activity of cortical neurons in the low-density culture (LD, $1 \times 10^{5} \mathrm{cells} / \mathrm{cm}^{2}$ ) rapidly decreased (Figure 1a). At $24 \mathrm{~h}$ after the start of culture, there was complete loss of activity. On the other hand, the decreasing rate of the activity in the high-density culture $(\mathrm{HD}$, $5 \times 10^{5}$ cells $/ \mathrm{cm}^{2}$ ) was much slower than that in the LD. Approximately $40 \%$ of the original activity was retained at $24 \mathrm{~h}$. However, there was no significant population of 5bromo-2'-deoxyuridine-positive cells throughout experiments (unpublished data), suggesting that the population of proliferative cells such as glia is negligible in this culture. When the $\mathrm{CM}$ factors prepared from the HD culture in a separate experiment was added to the LD culture at a $40 \%$ of the original $\mathrm{CM}$ from the beginning of culture, the decreasing rate of 2-(2-methoxy-4-nitrophenyl)-3-(4-nitrophenyl)-5-(2,4-disulfophenyl)-2H-tetrazolium monosodium salt (WST-8) survival activity was slowed to the level for HD culture (Figure 1a). In the experiments measuring the death rate by use of lactate 

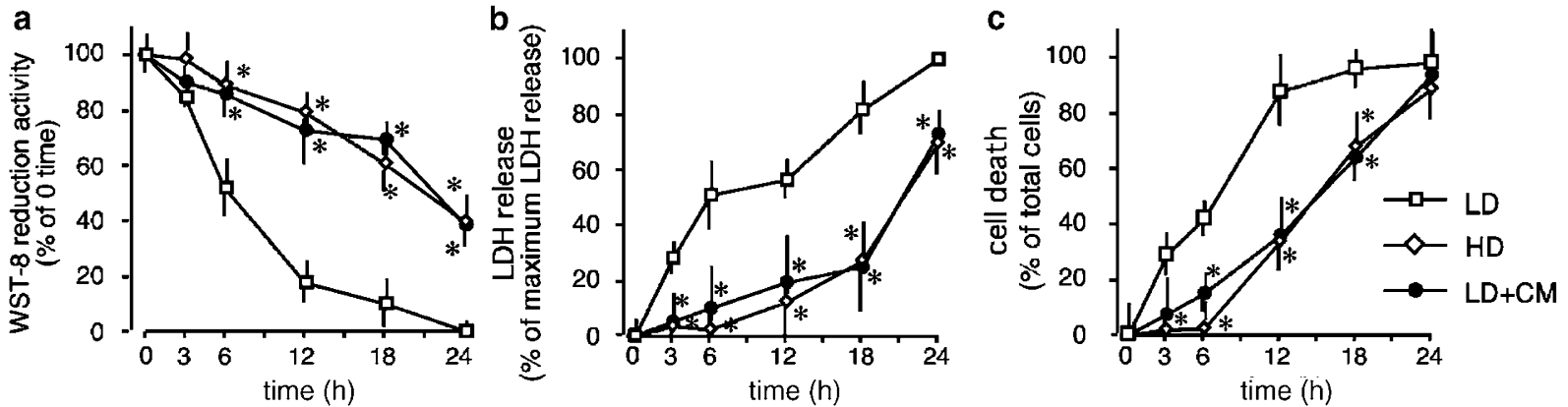

Figure 1 Conditioned medium CM factors-induced cell survival in cultured cortical neurons under serum-free conditions. Cortical neurons were cultured in the serumfree medium under low-density (LD), high-density (HD) and LD plus CM (LD+CM). The CM-concentration-dependent survival activity was measured by WST-8 assay. Culture dishes were precoated with a $40 \%$ equivalent of CM from HD culture. The time course of survival activity was measured by WST-8 assay (a), and cell death was measured by LDH release assay (b) and trypan blue exclusion test (c). Results are expressed as the means \pm S.E.M. from three independent experiments. ${ }^{\star} P<0.05$, compared with LD culture

dehydrogenase $(\mathrm{LDH})$ release assay kit, $28 \%$ of total $\mathrm{LDH}$ release in the LD culture was observed as early as $3 \mathrm{~h}$ from the start of culture, and reached a maximal at $24 \mathrm{~h}$ after the beginning of culture. However, significant LDH release was not observed at the time point of $6 \mathrm{~h}$, although the release was gradually increased at later time points in HD culture. The CM treatment decreased the $\mathrm{LDH}$ release in the LD culture to the level similar to the HD culture (Figure 1b). Quite similar results were observed when trypan blue exclusion assay was utilized for cell death activity (Figure 1c).

\section{CM-induced cell death mode switch}

Phase-contrast microscopic observation shows that most neurons under the LD condition lost the normal thickness in morphology except nuclei $12 \mathrm{~h}$ after the start of culture, while those in the HD or LD plus CM conditions retained the thickness, and had typical neurites (Figure $2 \mathrm{Aa}-\mathrm{C}$ ). And $24 \mathrm{~h}$ after the start of culture, most of the neurons in the HD or LD plus $\mathrm{CM}$ showed a reduction in cell size, and some showed a nuclear fragmentation (Figure 2Ad-f). fluorescein isothiocyanate (FITC)-conjugated annexin $\mathrm{V}$ has been utilized to detect that the externalization of phosphatidylserine occurred at an early stage of apoptosis. ${ }^{10}$ On the other hand, the staining of nuclei with propidium iodide $(\mathrm{PI})$ was performed to detect the plasma membrane damage, which is known to be a marker of necrosis. ${ }^{11}$ As shown in Figure $2 \mathrm{Ba}$, neurons were stained with $\mathrm{PI}$, but not with annexin $\mathrm{V}$ at the time point of as early as $3 \mathrm{~h} \mathrm{LD}$ culture. As previously reported, ${ }^{9}$ on the other hand, most neurons in the HD culture were PI negative, but annexin $\mathrm{V}$ positive instead (Figure 2Bb). By coating with $\mathrm{CM}$, PIpositive neurons were lost, while most stained ones were annexin V-positive instead (Figure 2Bc). The CM coating decreased the population of PI-positive neurons from $66.8 \%$ of total cells to $25.2 \%$, but increased that of annexin V-positive ones from 10.1 to $55.3 \%$ (Figure 2Bd). Furthermore, in the HD condition PI-positive neurons were $16.8 \%$ and annexin Vpositive neurons were $68.2 \%$ of the total cells.

The conversion of procaspase- 3 to active caspase- 3 is generally accepted to be a reliable indicator of apoptosis. ${ }^{12}$ As shown in Figure $2 \mathrm{Be}-\mathrm{h}$, no significant active caspase-3 signal was observed in the LD culture, while the CM coating
A
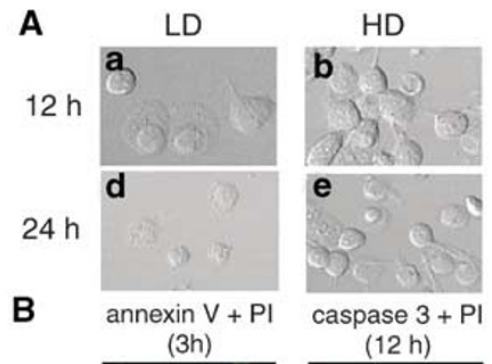

LD
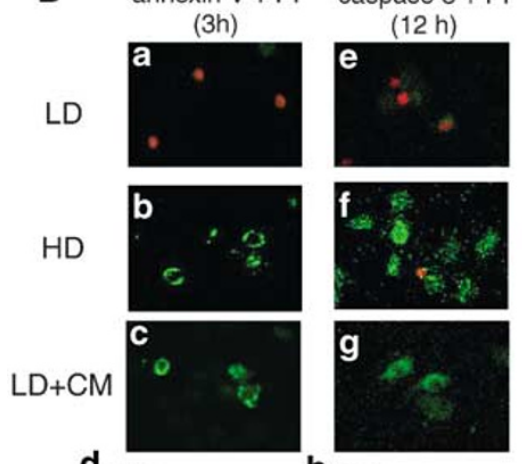

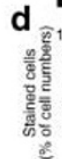
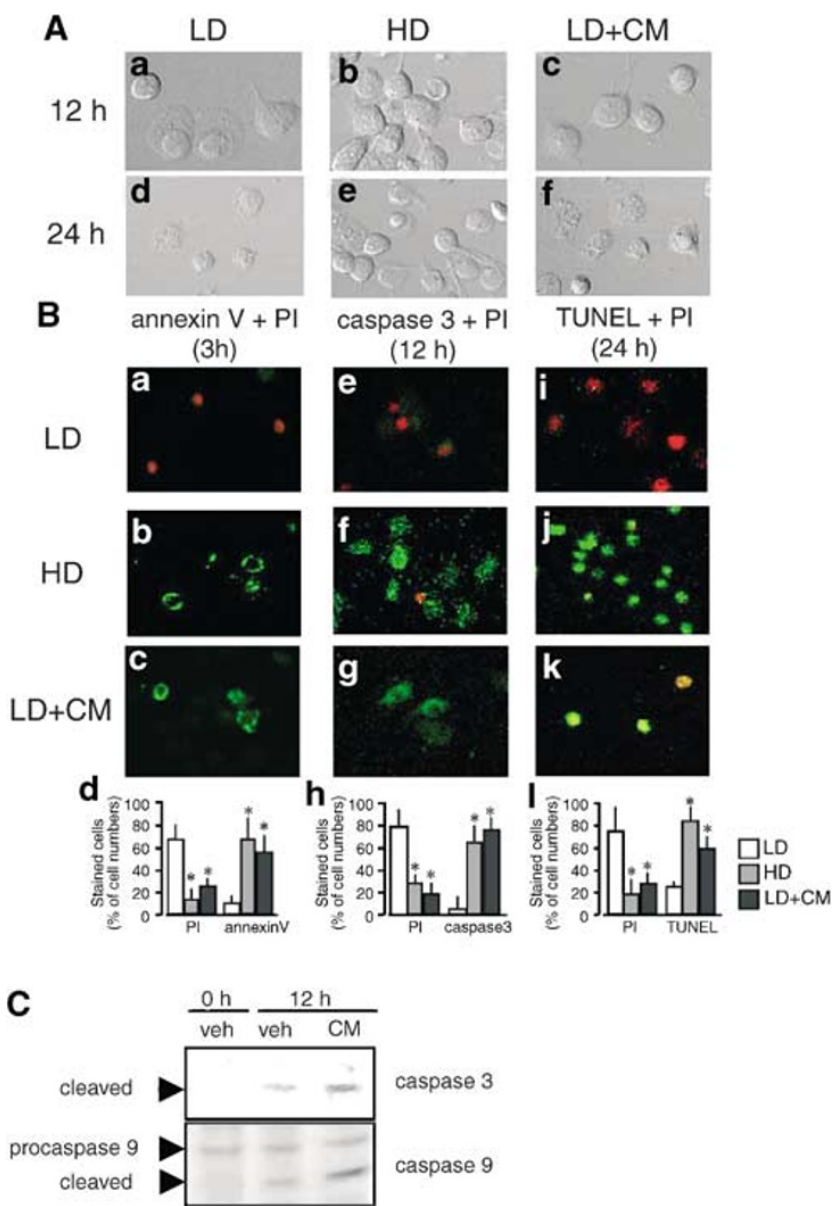

Figure 2 CM-induced cell death mode switch from necrosis to apoptosis. (A) Phase- contrast photographs of neurons in the LD, HD and LD+CM cultures. (B) Cell death mode switch. Neurons in LD, HD and LD+CM cultures were stained with PI (red) and annexin V (FITC labeled: green) (a, b and c), PI and active caspase-3 (FITC labeled: green) (e, $f$ and g), and PI and TUNEL (FITC labeled: green) ( $i, j$ and $k$ ) after incubation for 3,12 and $24 \mathrm{~h}$, respectively, and then observed under a confocal laser scanning microscope (confocal LSM). Quantitative comparisons of stained neurons (200-500 cells in each group) are shown with PI or annexin V (d), PI or active caspase-3 (h) and PI or TUNEL (I) between $L D(L), L D+C M(C)$ and $H D(H)$. Results are expressed as the means \pm S.E.M. from three independent experiments. ${ }^{*} P<0.05$, compared with LD culture. (C) Immunoblot analyses of protein expression of caspases-3 and -9 proteins after incubation for $12 \mathrm{~h}$ 
markedly increased the signal, which is maximal $12 \mathrm{~h}$ after the start of culture, as well as in the HD culture.

Terminal deoxunucleotidyl transferase-mediated dUTP nick end labeled (TUNEL) activity is another indicator for apoptosis. ${ }^{13}$ This activity was maximum $24 \mathrm{~h}$ after the start of HD or CM plus LD culture, but not in the LD culture (Figure $2 \mathrm{Bi}-\mathrm{I})$. At this time point, however, both TUNEL and PI signals were observed, presumably because apoptotic cells begin to show membrane damages at the late stage.

The activation of caspase-3 was also confirmed by immunoblot analysis (Figure 2C). There was no significant signal at the size for activated caspase-3 cleaved from procaspase- 3 in the cell lysates $0 \mathrm{~h}$ after the LD culture. A marked signal, however, was observed in the sample of $12 \mathrm{~h}$ culture in the presence of $\mathrm{CM}$, although less signal was also detected in the sample of $12 \mathrm{~h}$ culture in its absence. Quite a similar pattern of cleavage of procaspase-9 to activated caspase- 9 was also observed in these samples. However, the cleavage of procaspase-8 to activated caspase- 8 was less significant and there were no significant changes among these samples (data not shown). Thus, CM factors are unlikely to drive the apoptotic signaling through tumor necrosis factor (TNF) receptor family coupled to procaspase-8 cleavage.

\section{Electron microscopical observation of neuronal death}

After the negative staining of neurons cultured for 3 or $12 \mathrm{~h}$ under different conditions, electron microscopical observation was carried out. There was no significant change in membrane structure, mitochondria or nucleus $3 \mathrm{~h}$ after the start of LD culture (Figure $3 a$ and $b$ ). However, typical necrotic cell death features were observed in a representative neuron, in which there was decreased electron density in the cytoplasm, disrupted plasma membranes and grossly swollen mitochondria (Figure $3 c$ and d). Swollen mitochondria had no clear cristae structures. Marked membrane disruption was observed $12 \mathrm{~h}$ after the LD culture. The neuron in the HD culture, on the other hand, had marked nuclear fragmentation

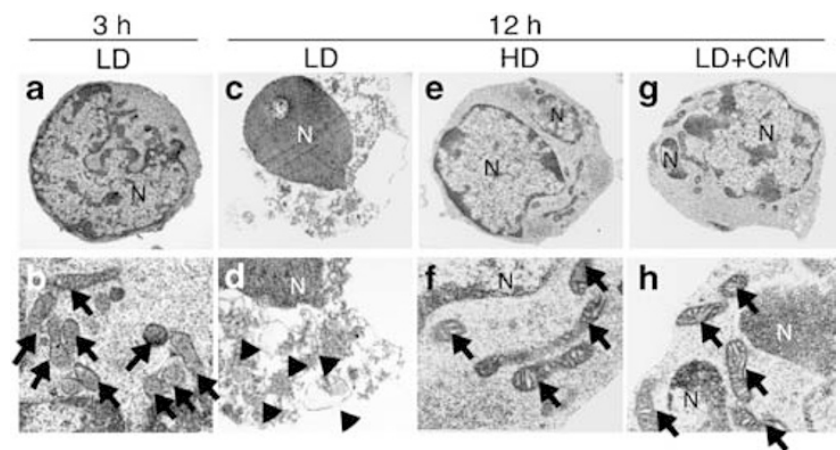

Figure 3 Necrotic and apoptotic neuronal death in TEM observation. Neurons $3 \mathrm{~h}(\mathrm{a})$ or $12 \mathrm{~h}(\mathrm{c}, \mathrm{e}, \mathrm{g})$ after start of LD $(\mathrm{a}, \mathrm{c}), \mathrm{HD}(\mathrm{e})$ and LD+CM (g) cultures, respectively, were used for TEM observation. High magnification of mitochondria in the LD (b: $3 \mathrm{~h}, \mathrm{~d}: 12 \mathrm{~h}$ ), HD (f: $12 \mathrm{~h}$ ) and LD+CM (l: $12 \mathrm{~h}$ ) cultures, respectively. Swollen mitochondria and intact mitochondria are indicated by arrowheads and arrows, respectively. $\mathrm{N}$ : nuclei with some condensed parts (Figure 3e), but mitochondria remained intact (Figure $3 f)$. The neuron in the LD culture in the presence of CM also retained the electron density and had nuclear fragmentation or chromatin condensation, but no marked swollen mitochondria (Figure $3 g$ and $h$ ).

\section{Phospholipase C mediates the action of CM factors}

Several lines of evidence indicate that the cytosolic $\mathrm{Ca}^{2+}$ concentration can regulate apoptosis. ${ }^{14,15}$ We examined the involvement of $\mathrm{Ca}^{2+}$-related mechanisms in $\mathrm{CM}$-induced neuronal survival. In the pharmacological experiments, all tested drugs affecting signal transduction, except for thapsigargin, were added to the $\mathrm{CM}$-coated plate as seeding (Figure $4 a)$. Thapsigargin is known to deplete $\mathrm{Ca}^{2+}$ from endoplasmic reticulum $\mathrm{Ca}^{2+}$ stores, including inositol. ${ }^{16,17}$ This compound concentration dependently inhibited the survival effects of $\mathrm{CM}$ in ranges of $0.1-10 \mu \mathrm{M}$. U73122, an aminosteroid inhibitor of phospholipase C (PLC) ${ }^{18}$ showed a concentration-dependent inhibition of the survival effect of $\mathrm{CM}$. The concentration showing maximal inhibition and the $\mathrm{IC}_{50}$ were 10 and $1.1 \mu \mathrm{M}$, respectively. In contrast, the same concentration ranges of U73343, an inactive analog of U73122, ${ }^{19}$ showed no inhibitory effect on the neuronal survival by CM (data not shown). Neither verapamil, nitrendipine nor $\omega$-conotoxin-GVIA, blockers for $\mathrm{L}$ and $\mathrm{N}$-type $\mathrm{Ca}^{2+}$ channel, inhibited effects even at $0.1-10 \mu \mathrm{M}$ (data not shown). These results suggest that PLC activation and the following elevation of intracellular $\mathrm{Ca}^{2+}$
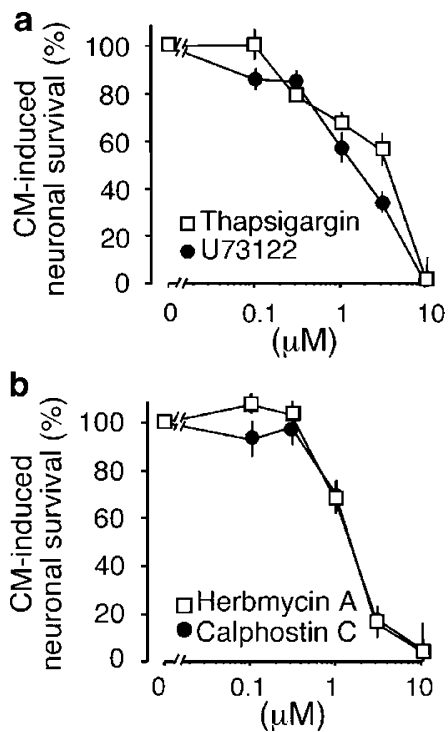

Figure 4 Signal transduction for the CM-induced neuronal survival. (a) Effects of various reagents affecting $\mathrm{Ca}^{2+}$ dynamics. Cortical cells were seeded at $1 \times 10^{5} \mathrm{cells} / \mathrm{cm}^{2}$ onto the plate previously coated with CM (40\%). Drugs were added to the culture at the beginning of the culture. Survival activity was measured by WST-8 $12 \mathrm{~h}$ after the start of culture. Neuronal survival was expressed as percentage of inhibition of specific absorbance in CM-coated cultures. Data show mean \pm S.E.M. from three independent experiments. (b) Effects of various protein kinase inhibitors. Treatments of cortical cells with reagents and WST-8 were carried out, as described in (a). Neuronal survival was expressed as percentage inhibition of specific absorbance in CM-coated cultures. Data show the mean \pm S.E.M from three independent experiments 
concentration are associated with neuronal survival activity in CM-coated cultures.

\section{Effects of various protein kinase inhibitors on $\mathrm{CM}$-actions}

It is well known that various protein kinases affect the cell survival or cell growth. A number of growth factors possessing neurotrophic activity stimulate tyrosine kinase (TK) domain within their receptor molecules and the TK stimulation could lead to protein kinase $\mathrm{C}$ (PKC) activation through PLC gamma stimulation, and to phosphatidylinositol-3 kinase (PI-3 kinase) activation. $^{20,21}$

Here, we examined the effects of inhibitors for various kinases on CM-induced survival. When herbimycin $\mathrm{A}$, a TK inhibitor interacting with sulfhydryl groups of the kinases, at $0.1-10 \mu \mathrm{M}$ was added to CM-coated cultures, it inhibited the survival activity of $\mathrm{CM}$ in a concentration-dependent manner (Figure 4b). Calphostin C (a highly selective, potent and membrane permeable PKC inhibitor) ${ }^{22}$ also concentrationdependently blocked the survival effects of $\mathrm{CM}$ within the ranges of $0.1-10 \mu \mathrm{M}$ (Figure $4 \mathrm{~b}$ ). However, there was no significant inhibition by KT 5720, a specific inhibitor of cyclic AMP-dependent protein kinase (PKA), ${ }^{23}$ wortmannin, which is an inhibitor of $\mathrm{Pl}-3$ kinase and myosin light-chain kinase, ${ }^{24,25}$ PD98059 and U0126, inhibitors for mitogen-activated protein kinase kinase (MAPKK), ${ }^{26-28}$ nor by KN93, an inhibitor for $\mathrm{Ca}^{2+} /$ calmodulin kinase II (data not shown). ${ }^{29}$

\section{CM-induced survival activity has critical time in the early stage of cell culture}

In order to examine the critical time, half-maximal concentration $(20 \%)$ of $\mathrm{CM}$ was added for limited periods to the LD culture and the survival activity was measured $12 \mathrm{~h}$ after the start of culture (Figure 5a). Without CM treatment, the WST-8 activity was $17.7 \%$. The CM treatment for $0-2,0-6$ or $0-12 \mathrm{~h}$ markedly increased the survival, but the treatment for 2-12 and $6-12 \mathrm{~h}$ did not. Thus, it is evident that the initial $2 \mathrm{~h}$ from the beginning of culture is the critical time for the CM-induced survival activity. As shown in Figure $5 b$, the addition of U73122 at $10 \mu \mathrm{M}$ for the initial $2 \mathrm{~h}$ markedly inhibited the $\mathrm{CM}$ induced survival activity to $4.4 \%$. However, the addition of U73122 during $2-12 \mathrm{~h}$ showed very limited effects $(68 \%$ of the control), while complete blockade was observed by the addition during $0-12 \mathrm{~h}$. Quite similar results were also observed with calphostin $\mathrm{C}$. On the other hand, the inhibitory effects of herbimycin A were observed only when added for long periods. Thus, the initial $2 \mathrm{~h}$ would be the critical period for CM-induced survival activity through PLC and PKC mechanisms.

\section{CM-stimulated PKC activity insensitive to herbimycin A}

As shown in Figure 6, basal PKC activity was constant in vehicle-treated LD culture throughout $0-12 \mathrm{~h}$ after the start of culture. The CM (40\%) coating of LD culture significantly increased PKC activity $2 \mathrm{~h}$ after the culture, while a smaller but
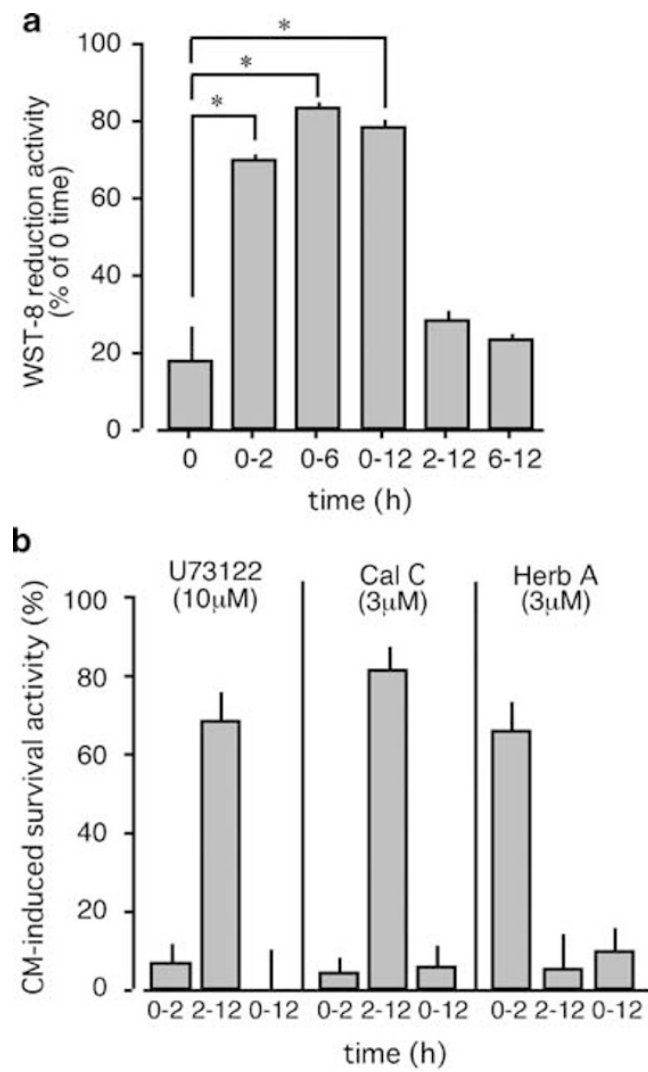

Figure 5 Critical period-specific inhibition of CM-induced survival activity by U73122, calphostin C or herbimycin A. (a) Survival effects of CM treatment during various periods. CM was added to the LD culture and incubated for the periods indicated in panel A. At the end of incubation with $\mathrm{CM}$, the medium was changed by the fresh one without $\mathrm{CM}$. To avoid the influences of residual $\mathrm{CM}$ after the washout procedure, $20 \%$ equivalent $\mathrm{CM}$ from $\mathrm{HD}$ culture was used only for this paradigm of experiments. The WST-8 assay was performed $12 \mathrm{~h}$ after the start of culture. Data are mean \pm S.E.M. from three independent experiments. (b) Cortical cells were seeded $1 \times 10^{5}$ cells $/ \mathrm{cm}^{2}$ onto the plate previously coated with $40 \% \mathrm{CM}$. Drugs were added to the culture during the indicated periods. Neuronal survival was expressed as percentage inhibition of specific absorbance in CM-coated cultures. Data show mean + S.E.M. from three independent experiments. ${ }^{*} P<0.05$

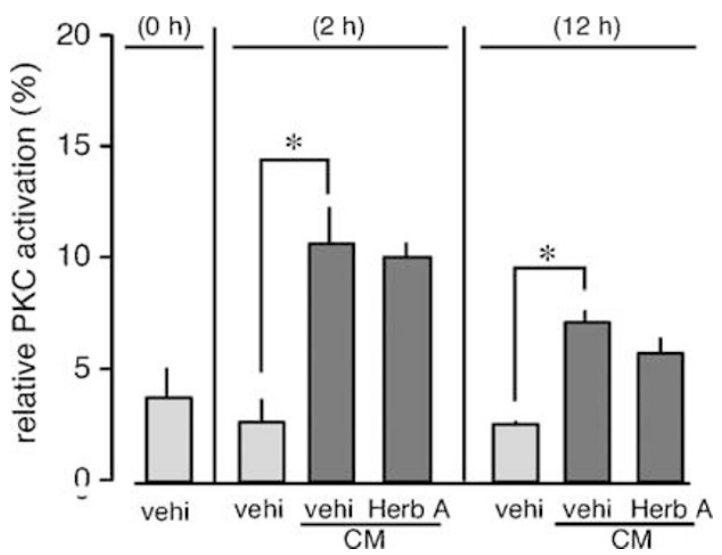

Figure 6 Lack of effects of herbimycin A on CM-induced PKC activation. Relative PKC activation was performed as described in Materials and methods. Results are expressed as the means \pm S.E.M. from three independent experiments. ${ }^{*} P<0.05$ 
significant increase was still observed at $12 \mathrm{~h}$. However, the addition of herbimycin $\mathrm{A}$ at $3 \mu \mathrm{M}$ did not affect the $\mathrm{CM}$-induced increase in PKC activation (Figure 6). The addition of calphostin $\mathrm{C}$ at $3 \mu \mathrm{M}$ completely abolished PKC activity in all these preparations (data not shown). Thus, it is suggested that receptor tyrosine kinases unlikely activate the CMinduced PKC activation, and thereby the inhibitory effect of U73122 is unlikely to be mediated through PLC gamma.

\section{Calphostin C-reversible CM-induced cell death mode switch}

The CM-induced cell death mode switch from necrosis to apoptosis was observed in the double staining of Hoechst 33342 and $\mathrm{PI} 12 \mathrm{~h}$ after the start of serum-free culture (Figure $7 a)$. In the vehicle-treated control LD culture, most of the neurons were PI positive, but had no significant condensed or fragmented nuclei stained by Hoechst 33342, apoptosis markers. The CM coating completely diminished the population of Pl-positive neurons, but increased the population showing condensed or fragmented nuclei. As shown in Figure $7 \mathrm{a}$ and $\mathrm{b}$, further addition of calphostin $\mathrm{C}$ at $3 \mu \mathrm{M}$ completely reversed the $\mathrm{CM}$-induced cell death mode switch, while the addition of herbimycin $\mathrm{A}$ at $3 \mu \mathrm{M}$ did not.
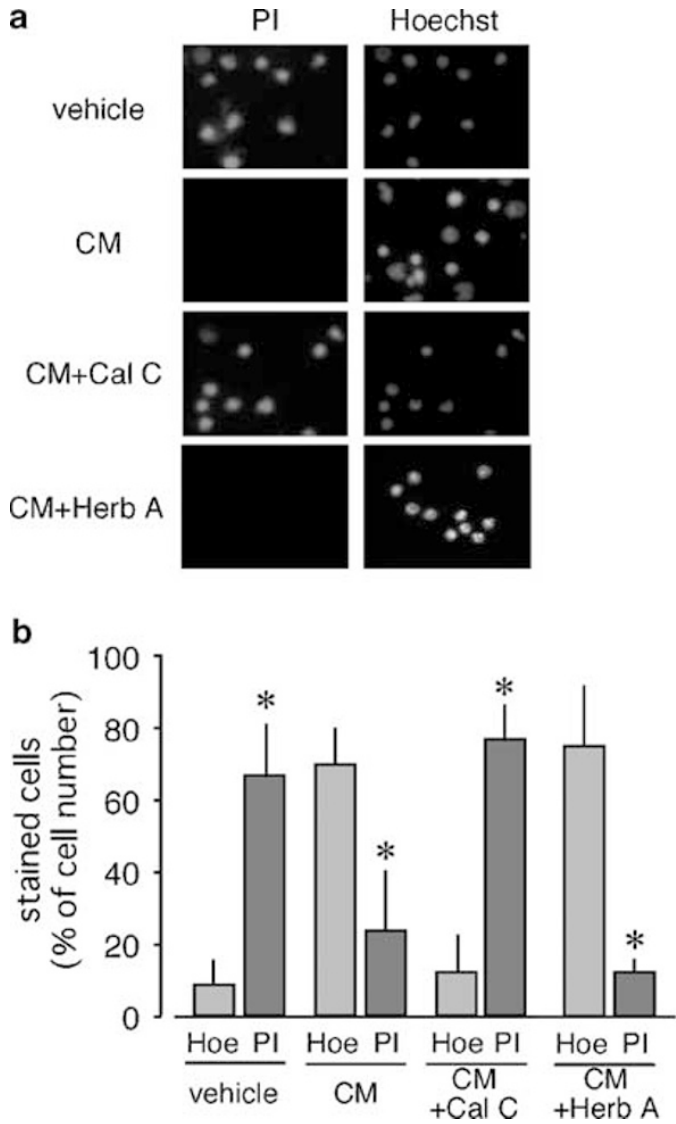

Figure 7 Calphostin C-reversible CM-induced cell death mode switch. (a and b) Double staining with Hoechst 33342 and $\mathrm{PI} 12 \mathrm{~h}$ after the start of serum-free culture and their quantitative comparisons. In these analyses, 500-800 cells in each group were counted. ${ }^{*} P<0.05$ compared with Hoechst 33342 -stained cells
Although little is known of the mechanisms for necrosis, the decrease in cellular ATP levels is reported to cause necrosis. ${ }^{30}$ As shown in Figure 8a, the LD culture showed a rapid drop in cellular ATP levels from the time point of $30 \mathrm{~min}$ to $12 \mathrm{~h}$ after the start of serum-free culture. The speed of decrease in ATP levels of both HD and CM plus LD cultures was significantly slower than the LD culture. The question is whether ATP levels determine the cell death mode switch. To answer this question, we attempted to see the effects of oligomycin, which decreases ATP levels by inhibiting $F_{0}-F_{1}$ ATPase in mitochondria. The addition of oligomycin at 1 and $10 \mu \mathrm{M}$ concentration dependently decreased the residual ATP levels (Figure 8b). The CM-induced increase in ATP levels was completely abolished by oligomycin at concentrations as low as $1 \mu \mathrm{M}$, which itself did not cause a significant decrease in the ATP levels of LD culture. Here, we used a minimum concentration of oligomycin $(1 \mu \mathrm{M})$ for the experiments to avoid nonspecific toxicity by a higher concentration of this reagent. The treatment with $1 \mu \mathrm{M}$ oligomycin reversed the $\mathrm{CM}$-induced cell death mode switch, as seen in the increased $\mathrm{PI}$ staining and decreased active caspase-3 signal (Figure 8c). To examine the mechanisms underlying CM-induced inhibition of rapid decrease in ATP levels in the serum-free and LD culture, $\left[{ }^{3} \mathrm{H}\right]-2$-deoxy glucose $\left(\left[{ }^{3} \mathrm{H}\right]-2-\mathrm{DG}\right)$ uptake activity was measured under various conditions. The $\left[{ }^{3} \mathrm{H}\right]-2-$ DG uptake was $4444.8 \mathrm{dpm} /$ well in the serum-containing LD culture, but $463.6 \mathrm{dpm} /$ well in the serum-free LD culture. The CM coating increased the activity to $2744.2 \mathrm{dpm} /$ well, and this increase was completely abolished by a further addition of U73122 $(10 \mu \mathrm{M})$ or calphostin $\mathrm{C}(3 \mu \mathrm{M})$, as shown in Figure $8 D$. These inhibitors alone showed no significant effect on the uptake activity (data not shown). The influences on ATP levels by CM, U73122 and calphostin $C$ were quite similar to the case with [ $\left.{ }^{3} \mathrm{H}\right]-2-D G$ uptake activity (Figure $8 \mathrm{e}$ ). Moreover, the cytochrome $c$ (cyto $c$ ) signal was colocalized with Mitotracker Red CMXRos, a fluorescent probe for mitochondria, $12 \mathrm{~h}$ after the start of serum-free culture (Figure 9), and it is evident that the apoptotic signal manifested by cyto $c$ release is not given under the serum-free condition. The CM coating clearly induced cyto $c$ release and this change was reversed by calphostin $\mathrm{C}$ at $3 \mu \mathrm{M}$. However, the addition of herbimycin $\mathrm{A}$ at $3 \mu \mathrm{M}$ did not affect the $\mathrm{CM}$-induced cyto $c$ release (Figure 9).

\section{Discussion}

Initially, we found the cell density-dependent survival activity of cortical neurons in the serum-free culture, in which there were no additional supplements to increase the survival. ${ }^{9,31}$ The coating and addition of CM prepared from the HD culture markedly increased the survival activity (data not shown). These results suggest that the soluble survival factors in $\mathrm{CM}$ have protein-like property to adhere to the substrate, and the cells (neurons) have membrane receptors to receive signals from such $\mathrm{CM}$ factors. In a preliminary study, we found that proteins migrating at sizes of 20 and $22 \mathrm{kDa}$ on SDS-PAGE called NDI 20 and 22 retain major survival activities, although a detailed comparison in signaling with the original CM factors remains to be determined. ${ }^{32}$ 

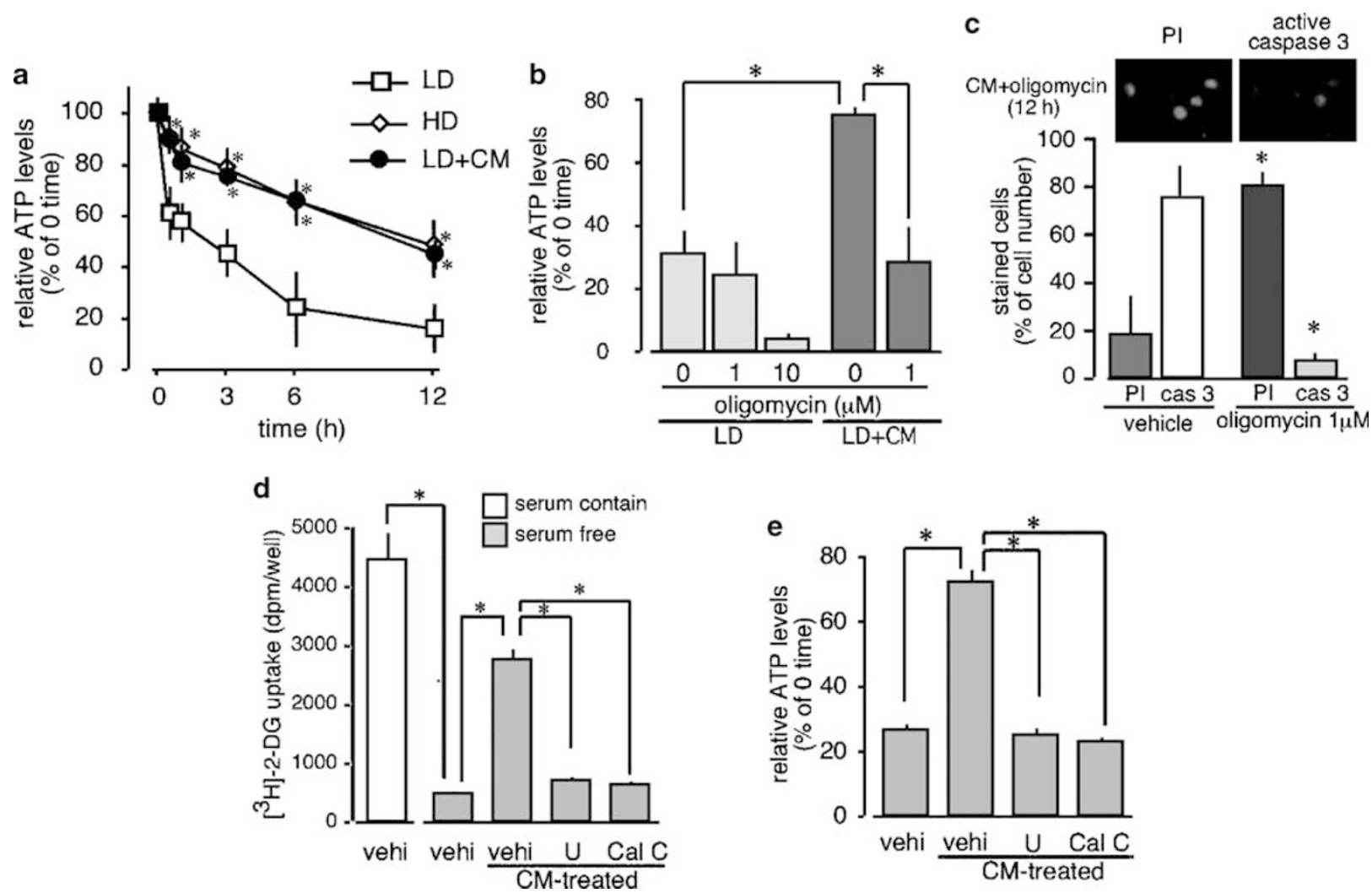

Figure 8 Calphostin C-reversible CM-induced maintenance of intracellular ATP. (a) Time course of changes in cellular ATP levels in LD, HD and LD+CM. Relative ATP levels were calculated as the percent of the time 0 level. Results are expressed as the means \pm S.E.M. from three independent experiments. ${ }^{*} P<0.05$ compared with LD culture. (b) Oligomycin-reversible increases in ATP levels by CM treatment. (c) Oligomycin-reversible CM-induced switch of necrosis to apoptosis as seen in PI and active caspase-3 double staining and quantitative comparisons of stained cells. In this analysis, 500-800 cells in each group were counted. (d) Effects of U73122 and calphostin $\mathrm{C}$ on $\left[{ }^{3} \mathrm{H}\right]-2-\mathrm{DG}$ uptake for $2 \mathrm{~h}$ immediately after the start of culture. (e) Inhibition of CM-induced increase in ATP levels by U73122 (10 $\left.\mu \mathrm{M}\right)$ and calphostin C $(3 \mu \mathrm{M}) .{ }^{\star} P<0.05$

The cell density-dependent and CM-induced survival activity could be evaluated as the delay of cell death, as shown in Figure 2A. The phase-contrast microscopical analysis showed that the cells in the HD culture or those in the LD plus CM culture were healthy and extended neurites $12 \mathrm{~h}$ after the start of culture. However, most of the cells in such HD or LD plus CM cultures, but not in the LD culture, $24 \mathrm{~h}$ after the start of culture showed a reduction in cell size, and some showed a nuclear fragmentation. This difference in the cell death mode was further characterized in the sense of necrosis and apoptosis. As expected, the dead cells in the LD culture were PI positive and characterized to be necrotic ones, while those in the HD or LD plus CM culture were found to be apoptotic ones. In these experiments, necrotic cells were characterized by PI staining and broken cell membranes in transmission electron microscopy (TEM) (Figure 3c), while apoptotic cells were annexin $\mathrm{V}$, activated caspase- 3 and TUNEL-positive (Figures 3 and 2B). They also showed nuclear condensation and fragmentation in fluorescent microscopy after staining with Hoechst 33342, and in TEM (Figures $7 \mathrm{a}$ and 3 ). These results strongly suggest that $\mathrm{CM}$ factors secreted from the serum-free culture may cause the cell death mode switch from necrosis to apoptosis.

The next issue to be discussed is the molecular mechanism underlying CM-mediated survival. In many cases, $\mathrm{Ca}^{2+}$ dynamics and kinase activities are important regulators that affect cell survival. ${ }^{33,34}$ From the study using various inhibitors to affect cellular $\mathrm{Ca}^{2+}$ dynamics, PLC and its downstream $\mathrm{Ca}^{2+}$ mobilization from endoplasmic reticulum were found to be involved in $\mathrm{CM}$-induced neuronal survival. Among various kinases, PKC and tyrosine kinases are likely candidates involved in these mechanisms. When the time period of neurons to be exposed to $\mathrm{CM}$ is varied, the critical period to induce survival activity was found to be within $2 \mathrm{~h}$ after the start of culture. This is also supported by data using protein kinase inhibitors, in which calphostin $C$, but not herbimycin $A$, critically inhibited $\mathrm{CM}$-induced survival activity only when added for the initial $2 \mathrm{~h}$. It should be noted that the CM-induced PKC activation lasts for at least $12 \mathrm{~h}$. All these results suggest that PKC activation is an essential mechanism for CMmediated survival activity, but some other unidentified mechanisms determine the critical period.

Although longer incubation with herbimycin A inhibited CMinduced survival activity, it has no effect on CM-stimulated PKC activity (Figure 6) or CM-induced cell death mode switch, characterized by the inhibition of necrosis (PI staining in Figure 7a) and induction of apoptosis (nuclear fragmentation and condensation in Figure 7a, and cyto $c$ release in Figure 9). Moreover, the phosphorylation of PLC gamma, which is mediated by TK receptor activation, was not observed in the 


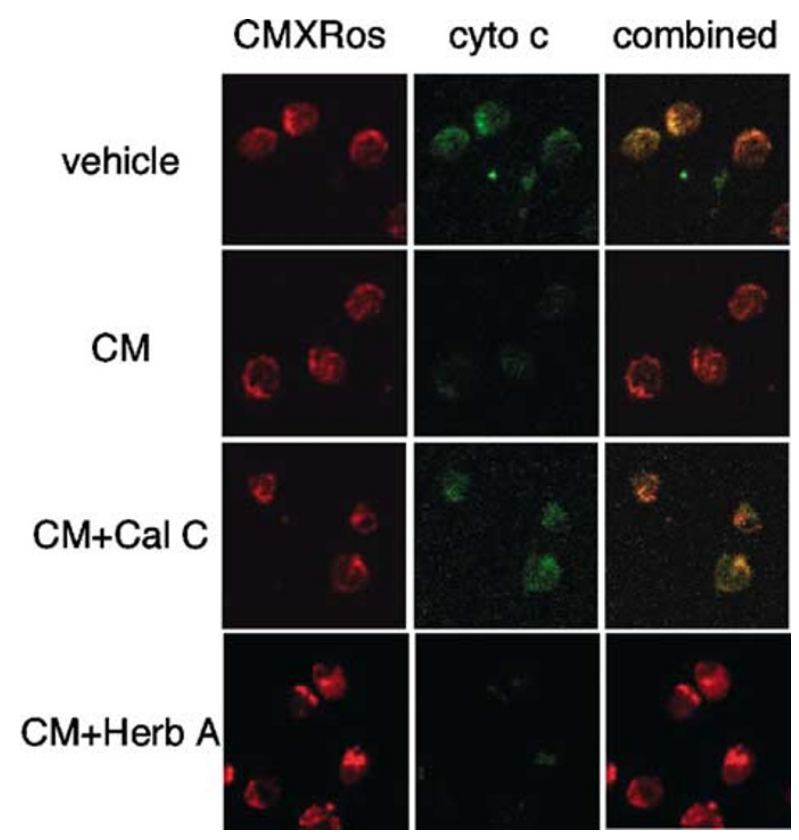

Figure 9 Calphostin $\mathrm{C}$-reversible cyto $c$ release by $\mathrm{CM}$. Mitochondria membrane potential $\Delta \Psi_{\mathrm{m}}$ (CMXRos: red) and cyto $c$ (FITC labeling: green; cyto $c)$ staining were observed in cortical neurons treated with vehicle, $\mathrm{CM}$, $\mathrm{CM}+$ calphostin $\mathrm{C}(3 \mu \mathrm{M})$ or $\mathrm{CM}$ +herbimycin $\mathrm{A}(3 \mu \mathrm{M})$ in the serum-free and $\mathrm{LD}$ culture. Mitochondria from vehicle- and $\mathrm{CM}+$ calphostin $\mathrm{C}$-treated cells show a high level of staining for cyto $c$. In contrast, mitochondria from $\mathrm{CM}$ - and $\mathrm{CM}+$ herbimycin A-treated cells show extensive loss of cyto $c$ staining. Combined images were produced by superimposing CMXRos (red) and cyto $c$ (green) staining. Yellow areas are indicative of colocalized CMXRos and cyto $c$ staining

immunoblot analysis of cortical neurons following CM treatment (data not shown). All these results strongly suggest that the survival activities of $\mathrm{CM}$ showing critical period and cell death mode switch are not mediated through TK receptors. The mechanisms underlying herbimycin A-induced inhibition of survival activity independent of possessing a critical period remain to be determined.

Although little is known of the mechanisms for necrosis, the decrease in cellular ATP levels is reported to cause necrosis. In a previous report, the reduction of cellular ATP levels by oligomycin switched the Fas ligand-induced apoptosis to necrosis. ${ }^{31}$ This view is supported by the present study, in which the rapid decrease in ATP levels was observed in the LD culture, but not in the HD culture or CM plus LD culture (Figure 8a). Further analyses revealed that $\mathrm{CM}$ reversed the poor $\left[{ }^{3} \mathrm{H}\right]-2-D G$ uptake activity and rapid decrease in ATP levels, and these actions were abolished by calphostin $C$ (Figure $8 \mathrm{~d}$ and e). Thus, it is suggested that PKC activation by $\mathrm{CM}$ factors may activate glucose uptake and cause a subsequent increase in ATP levels. Although details of the mechanisms remain to be determined, there are some reports that PKC enhances the membrane translocation of the glucose transporter. ${ }^{35-38}$

As there was no significant cyto $c$ release from mitochondria, a known marker event for apoptosis, in the serum-free and LD culture (Figure 9), the serum-free stress itself unlikely causes proapoptotic mechanisms. We observed an activation of caspase-3 under the condition of HD or CM plus LD culture (Figure 2B and C). As an activation of caspase-8 was not observed in such cultures (data not shown), the apoptogenic mechanisms are unlikely through a family of TNF receptors. Instead, cyto $c$ release and caspase- 9 activation were observed (Figures 9 and $2 \mathrm{C}$ ). Thus, it is suggested that some $\mathrm{CM}$ factors may affect the cyto $c$ release from mitochondria, possibly through Bax or some other related proapoptotic $\mathrm{Bcl}-2$ family proteins. In addition, PKC activation may also be related to the $\mathrm{CM}$-induced cyto $c$ release or apoptosis.

In conclusion, the CM factors secreted from the HD culture caused the cell death mode switch from necrosis to apoptosis in the serum-free culture. Pharmacological analyses revealed that PKC is involved in their mechanisms for inhibition of necrosis and induction of apoptosis.

\section{Materials and Methods}

\section{Primary culture}

Primary culture of the cerebral cortex from 17 days of embryonic rats was performed according to the previously reported protocol. ${ }^{31,39}$ They were seeded onto 96-well culture dishes, eight-well Lab-Tek ${ }^{\mathrm{TM}}$ chambers, and 3.5- and $9.0-\mathrm{cm}$ culture dishes that had all been coated with poly-DLornithine (Sigma, St. Louis, MO, USA), and cultured in DMEM/F-12 medium at $37^{\circ} \mathrm{C}$ in $5 \% \mathrm{CO}_{2}$ atmosphere. $\mathrm{CM}$ was prepared from $\mathrm{HD}$ cultures $\left(5 \times 10^{5}\right.$ cells $\left./ \mathrm{cm}^{2}\right) 3$ days after the start of culture, filtrated through a Milex filter (Millipore, Bedford, MA, USA) and frozen at $-20^{\circ} \mathrm{C}$ until use. For $\mathrm{CM}$ coating, $40 \%$ of the original $\mathrm{CM}$ was added to culture dishes and incubated for $2 \mathrm{~h}$ at $25^{\circ} \mathrm{C}$. The dishes were washed twice with phosphate-buffered saline (PBS) for immediate use.

\section{LDH release assay}

Cell damage was quantified by measuring activities of the cytosolic LDH released into the culture medium from damaged cells, by use of the Cytotoxicity Detection Kit from Roche Molecular Biochemicals (Mannheim, Germany) according to the manufacturer's instructions. Briefly, cells $\left(3.2 \times 10^{3} \mathrm{cells} / 100 \mu \mathrm{l} / \mathrm{well}\right)$ were seeded on a 96 -well culture dish. For maximum LDH release, $100 \mu \mathrm{l}$ of $2 \%$ Triton $\mathrm{X}-100$ was added to the culture $(100 \mu \mathrm{l})$ and incubated for $30 \mathrm{~min}$ at $25^{\circ} \mathrm{C}$. Aliquots $(100 \mu \mathrm{l})$ of lysates were transferred to a 96-well dish and then the reaction mixture $(100 \mu \mathrm{l})$ from the kit was added to the wells and incubated for $90 \mathrm{~min}$ at $25^{\circ} \mathrm{C}$ in the dark. Enzyme activity was evaluated by colorimetry. For LDH release into the culture medium from cells at corresponding periods, aliquots $(50 \mu \mathrm{l}$ ) of culture medium were transferred to a 96 -well dish, $50 \mu \mathrm{l}$ of $2 \%$ Triton X-100 was added, and followed by the procedures mentioned above. Results were represented as the percentage of the maximum LDH release.

\section{WST-8 assay}

To assess the viability of cells, we performed WST-8 reduction assay kit (Dojin Lab., Tokyo, Japan) according to the manufacturer's instructions. WST-8 was added to the culture for $3 \mathrm{~h}$ at $37^{\circ} \mathrm{C}$ prior to the colorimetry. The percentage of WST- 8 activity was represented as the ratio of activity at different time points to that in the beginning of culture.

\section{Trypan blue exclusion assay}

To assess the neuronal cell death, an equal volume of $0.4 \%$ trypan blue was added to the culture, followed by twice washing with ice-cold PBS and 
fixation with $4 \%$ paraformaldehyde (PFA) in PBS for $30 \mathrm{~min}$ at $25^{\circ} \mathrm{C}$. Stained cells were evaluated as dead ones, and results were represented by the percentage of dead cells among the total cells.

\section{Measurement of intracellular ATP levels}

Intracellular ATP levels were measured by the luciferin-luciferase method, using the ATP-Determination Kit (Molecular Probes, Eugene, OR, USA). ${ }^{40}$ Entire cells of culture including any floating cells $\left(2 \times 10^{6}\right.$ cells) were subjected to the assay. The cells were washed twice with ice-cold PBS and suspended in cell dilution buffer (4 mM EDTA, $100 \mathrm{mM}$ Tris- $\mathrm{HCl} \mathrm{pH}$ 7.75). Aliquots $(20 \mu \mathrm{l})$ of cell lysates were added with the reaction solution $(200 \mu \mathrm{l})$ containing $0.5 \mathrm{mM}$ luciferin, $1.25 \mu \mathrm{g} / \mathrm{ml}$ luciferase and $1 \mathrm{mM}$ DTT from the kit, and used for bioluminescence assay, using LUMAT LB 9507 from EG\&G Berthold (Bad Wildbad, Germany).

\section{Annexin V-binding and PI-staining assay}

To assess the simultaneous observation of the early phase of apoptotic and necrotic features, cortical cells on an eight-well Lab-Tek ${ }^{\mathrm{TM}}$ chamber were treated with annexin V fluorescein (Annexin V-FLUOS Staining Kit from Roche Molecular Biochemicals) and $10 \mu \mathrm{g} / \mathrm{ml} \mathrm{PI}$ for $15 \mathrm{~min}$ at $25^{\circ} \mathrm{C}$ in the dark. Cells were washed once with ice-cold PBS, fixed with 4\% PFA in PBS for $30 \mathrm{~min}$ at $25^{\circ} \mathrm{C}$ and observed under a fluorescence microscope (LSM 410; Carl Zeiss, Tokyo, Japan).

\section{Immunocytochemistry of caspase-3}

Cortical cells on an eight-well Lab-Tek ${ }^{\mathrm{TM}}$ chamber were fixed with $4 \%$ PFA in PBS for $30 \mathrm{~min}$, followed by permeabilization using $0.1 \%$ Triton $X-100$ in PBS. They were incubated in blocking buffer (2\% low-fat milk powder, $2 \%$ bovine serum albumin, $0.1 \%$ Tween-20, in PBS, pH 7.4) for $1 \mathrm{~h}$ at $25^{\circ} \mathrm{C}$. Anticleaved caspase-3 antibody (1:50; Cell Signaling, Tokyo, Japan) was added to the cells. After $2 \mathrm{~h}$ incubation at $25^{\circ} \mathrm{C}$ and washing, the cells were incubated with FITC-conjugated anti-rabbit immunoglobulin $(\operatorname{lgG})(1: 200$; Cappel, Aurora) for $4 \mathrm{~h}$ at $25^{\circ} \mathrm{C}$. Immunolabeled cells were observed under a fluorescence microscope.

\section{Transmission electron microscopy}

Cultured cortical neurons were fixed with $2.5 \%$ glutaraldehyde in $0.1 \mathrm{M}$ phosphate buffer $(\mathrm{pH} 7.4)$ for $1 \mathrm{~h}$ at $25^{\circ} \mathrm{C}$. The fixed cortical neurons were postfixed with $1 \%$ osmium tetroxide for $1 \mathrm{~h}$ at $25^{\circ} \mathrm{C}$, dehydrated in graded alcohol series, and embedded in Epon812. Ultrathin sections ( $80 \mathrm{~nm}$ thick) were cut with an Ultracut S (Leica, Austria), and then stained with uranyl acetate and lead citrate for 30 and $5 \mathrm{~min}$, respectively. The stained sections were observed under an electron microscope (JEM-1210; JEOL, Tokyo, Japan).

\section{Immunoblot analysis}

SDS-PAGE electrophoresis by using $12 \%$ polyacrylamide gel and immunoblot analysis were performed as described. ${ }^{41}$ Anticaspase- 8 and anti-caspase-9 antibody (1:500; StressGen, Victoria, Canada) and anticleaved caspase-3 antibody (1:500; Cell Signaling, Tokyo, Japan) were used as primary antibodies. Visualization of immunoreactive bands was performed using an enhanced chemiluminescent substrate (Super Signaling Substrate; Pierce Chemical Co., Rockford, IL, USA) for the detection of horseradish peroxides.

\section{$\left[{ }^{3} \mathrm{H}\right]-2-D G$ uptake}

$\left[{ }^{3} \mathrm{H}\right]-2-\mathrm{DG}$ (NEN, Boston, MA, USA) uptake was measured using modified Koivisto's methods. ${ }^{42}$ Briefly, $\left[{ }^{3} \mathrm{H}\right]-2-\mathrm{DG}(1 \mu \mathrm{Ci} /$ well, $10 \mathrm{nM})$ was added to the six-well culture dishes at the beginning of culture and incubated for $2 \mathrm{~h}$ at $37^{\circ} \mathrm{C}$ in a $5 \%-\mathrm{CO}_{2}$ atmosphere. Uptake of $\left[{ }^{3} \mathrm{H}\right]-2-\mathrm{DG}$ was terminated by a rapid removal of medium, followed by twice washing with ice-cold PBS (pH 7.4). The cells were lysed in $100 \mu$ of $0.5 \mathrm{M} \mathrm{NaOH}$, followed by neutralization with $0.5 \mathrm{M} \mathrm{HCl}$. The radioactivity of collected cell lysates was determined by a liquid-scintillation counter.

\section{PKC kinase assay}

Cultured cells were harvested using a solution containing $0.3 \% \beta$ mercaptoethanol, $5 \mathrm{mM}$ EDTA, $10 \mathrm{mM}$ EGTA, $50 \mu \mathrm{g} / \mathrm{ml} \mathrm{PMSF}, 10 \mathrm{mM}$ benzamidine and $50 \mathrm{mM}$ Tris- $\mathrm{HCl}(\mathrm{pH} \mathrm{7.5)}$, homogenized on ice and added to an equal volume of glycerol. PKC assay was performed using a PKC enzyme assay system (Amersham Pharmacia Biotech, Piscataway, $\mathrm{NJ}$, USA), according to the manufacturer's instructions with modifications. Briefly, samples (S) were incubated with the substrate peptide to be phosphorylated by PKC in $50 \mathrm{mM}$ Tris- $\mathrm{HCl}(\mathrm{pH} 7.5), 30 \mathrm{mM}$ dithiothreitol and $\left[\gamma-{ }^{32} \mathrm{P}\right]$ ATP in magnesium ATP buffer (1.2 $\mathrm{mM}$ ATP, $30 \mathrm{mM}$ HEPES and $72 \mathrm{mM} \mathrm{MgCl}_{2}, \mathrm{pH} 7.4$ ) for $15 \mathrm{~min}$ at $37^{\circ} \mathrm{C}$. Maximum PKC activation (Max) was obtained by the further addition of $0.3 \mathrm{mg} / \mathrm{ml} \mathrm{L} \alpha$-phosphatidyl-Lserine, $24 \mu \mathrm{g} / \mathrm{ml}$ phorbol 12-myristate 13-acetate and $12 \mathrm{mM}$ calcium acetate in $50 \mathrm{mM}$ Tris- $\mathrm{HCl}$ (pH 7.5). Background activation (B) was obtained by omitting substrate peptide from (S) reaction mixture. After the addition of stop solution, the reaction mixture was transferred onto peptide binding paper. These papers were washed twice with $5 \%$ acetic acid and the incorporation of ${ }^{32} \mathrm{P}$ into peptide was determined by a liquidscintillation counter. PKC activation was calculated by the following equation. PKC activation $(\%)=((\mathrm{S})-(\mathrm{B})) /((\mathrm{Max})-(\mathrm{B})) \times 100$.

\section{Statistical analysis}

Statistical analysis was carried out using Student's $t$-test following multiple comparisons of the analysis of variance (ANOVA). The criterion of significance was set at ${ }^{*} P<0.05$. All results are expressed as the mean \pm S.E.M.

\section{Acknowledgments}

We gratefully acknowledge M Niwa, S Izumi and T Koji for critical discussions, and N Fukushima and W Hamabe for technical help. Parts of this study were supported by Grants-in-Aid and Special Coordination Funds from the Ministry of Education, Culture, Sports, Science and Technology, Japan.

\section{References}

1. Becker KJ. (1998) Inflammation and acute stroke. Curr. Opin. Neurol. 11: 4549

2. Dirnagl U, ladecola $C$ and Moskowitz MA (1999) Pathobiology of ischaemic stroke: an integrated view. Trends Neurosci. 22: 391-397

3. Furlan M, Marchal G, Viader F, Derlon JM and Baron JC (1996) Spontaneous neurological recovery after stroke and the fate of the ischemic penumbra. Ann. Neurol. 40: 216-226

4. Linnik MD, Zobrist RH and Hatfield MD (1993) Evidence supporting a role for programmed cell death in focal cerebral ischemia in rats. Stroke 24: 20022008; discussion 2008-2009 
5. Lipton P (1999) Ischemic cell death in brain neurons. Physiol. Rev. 79: 14311568

6. Nishikawa A, Sodum R and Chung FL (1992) Acute toxicity of trans-4-hydroxy2-nonenal in Fisher 344 rats [corrected]. Lipids 27: 54-58

7. Toyokuni S, Luo XP, Tanaka T, Uchida K, Hiai H and Lehotay DC (1997) Induction of a wide range of $C(2-12)$ aldehydes and $C(7-12)$ acyloins in the kidney of Wistar rats after treatment with a renal carcinogen, ferric nitrilotriacetate. Free Radical. Biol. Med. 22: 1019-1027

8. Moroni F, Meli E, Peruginelli F, Chiarugi A, Cozzi A, Picca R, Romagnoli P, Pellicciari R and Pellegrini-Giampietro DE (2001) Poly(ADP-ribose) polymerase inhibitors attenuate necrotic but not apoptotic neuronal death in experimental models of cerebral ischemia. Cell Death Differ. 8: 921-932

9. Fujita R, Yoshida A, Mizuno K and Ueda $H$ (2001) Cell density-dependent death mode switch of cultured cortical neurons under serum-free starvation stress. Cell. Mol. Neurobiol. 21: 317-324

10. Martin SJ, Reutelingsperger CP, McGahon AJ, Rader JA, van Schie RC LaFace DM and Green DR (1995) Early redistribution of plasma membrane phosphatidylserine is a general feature of apoptosis regardless of the initiating stimulus: inhibition by overexpression of Bcl-2 and Abl. J. Exp. Med. 182: 1545-1556

11. Bal-Price A and Brown GC (2000) Nitric-oxide-induced necrosis and apoptosis in PC12 cells mediated by mitochondria. J. Neurochem. 75: 1455-1464

12. Green DR and Reed JC (1998) Mitochondria and apoptosis. Science 281: 1309-1312

13. Gavrieli $Y$, Sherman $Y$ and Ben-Sasson SA (1992) Identification of programmed cell death in situ via specific labeling of nuclear DNA fragmentation. J. Cell Biol. 119: 493-501

14. Koike T, Martin DP and Johnson Jr EM (1989) Role of $\mathrm{Ca}^{2+}$ channels in the ability of membrane depolarization to prevent neuronal death induced by trophic-factor deprivation: evidence that levels of internal $\mathrm{Ca}^{2+}$ determine nerve growth factor dependence of sympathetic ganglion cells. Proc. Natl. Acad. Sci. USA 86: $6421-6425$

15. Lipton $S A$ and Nicotera $P$ (1998) Calcium, free radicals and excitotoxins in neuronal apoptosis. Cell Calcium 23: 165-171

16. Thastrup O, Cullen PJ, Drobak BK, Hanley MR and Dawson AP (1990) Thapsigargin, a tumor promoter, discharges intracellular $\mathrm{Ca}^{2+}$ stores by specific inhibition of the endoplasmic reticulum $\mathrm{Ca}^{2+}-$ ATPase. Proc. Natl. Acad. Sci. USA 87: 2466-2470

17. Lupu-Meiri M, Beit-Or A, Christensen SB and Oron Y (1993) Calcium entry in Xenopus oocytes: effects of inositol trisphosphate, thapsigargin and DMSO. Cell Calcium 14: 101-110

18. Bleasdale JE, Thakur NR, Gremban RS, Bundy GL, Fitzpatrick FA, Smith RJ and Bunting S (1990) Selective inhibition of receptor-coupled phospholipase Cdependent processes in human platelets and polymorphonuclear neutrophils. J. Pharmacol. Exp. Ther. 255: 756-768

19. Smith RJ, Sam LM, Justen JM, Bundy GL, Bala GA and Bleasdale JE (1990) Receptor-coupled signal transduction in human polymorphonuclear neutrophils: effects of a novel inhibitor of phospholipase C-dependent processes on cell responsiveness. J. Pharmacol. Exp. Ther. 253: 688-697

20. Heumann R (1994) Neurotrophin signalling. Curr. Opin. Neurobiol. 4: 668-679

21. Hetman $M$ and $X i a Z$ (2000) Signaling pathways mediating anti-apoptotic action of neurotrophins. Acta Neurobiol. Exp. (Warsz) 60: 531-545

22. Kobayashi E, Nakano H, Morimoto M and Tamaoki T (1989) Calphostin C (UCN-1028C), a novel microbial compound, is a highly potent and specific inhibitor of protein kinase C. Biochem. Biophys. Res. Commun. 159: 548-553

23. Kase $\mathrm{H}$, Iwahashi $\mathrm{K}$, Nakanishi $\mathrm{S}$, Matsuda $\mathrm{Y}$, Yamada $\mathrm{K}$, Takahashi $\mathrm{M}$, Murakata C, Sato A and Kaneko M (1987) K-252 compounds, novel and potent inhibitors of protein kinase $\mathrm{C}$ and cyclic nucleotide-dependent protein kinases. Biochem. Biophys. Res. Commun. 142: 436-440

24. Powis G, Bonjouklian R, Berggren MM, Gallegos A, Abraham R, Ashendel C, Zalkow L, Matter WF, Dodge J, Grindey G and Vlahos CJ (1994) Wortmannin, a potent and selective inhibitor of phosphatidylinositol-3-kinase. Cancer Res. 54: 2419-2423

25. Yano H, Nakanishi S, Kimura K, Hanai N, Saitoh Y, Fukui $Y$, Nonomura $Y$ and Matsuda $Y$ (1993) Inhibition of histamine secretion by wortmannin through the blockade of phosphatidylinositol 3-kinase in RBL-2H3 cells. J. Biol. Chem. 268: 25846-25856

26. Alessi DR, Cuenda A, Cohen P, Dudley DT and Saltiel AR (1995) PD 098059 is a specific inhibitor of the activation of mitogen-activated protein kinase kinase in vitro and in vivo. J. Biol. Chem. 270: 27489-27494

27. Dudley DT, Pang L, Decker SJ, Bridges AJ and Saltiel AR (1995) A synthetic inhibitor of the mitogen-activated protein kinase cascade. Proc. Natl. Acad. Sci. USA 92: 7686-7689

28. Favata MF, Horiuchi KY, Manos EJ, Daulerio AJ, Stradley DA, Feeser WS, Van Dyk DE, Pitts WJ, Earl RA, Hobbs F, Copeland RA, Magolda RL, Scherle PA and Trzaskos JM (1998) Identification of a novel inhibitor of mitogen-activated protein kinase kinase. J. Biol. Chem. 273: 18623-18632

29. Sumi $M$, Kiuchi $K$, Ishikawa $T$, Ishii $A$, Hagiwara $M$, Nagatsu $T$ and Hidaka $H$ (1991) The newly synthesized selective $\mathrm{Ca}^{2+} /$ calmodulin dependent protein kinase II inhibitor KN-93 reduces dopamine contents in PC12h cells. Biochem. Biophys. Res. Commun. 181: 968-975

30. Eguchi Y, Shimizu S and Tsujimoto Y (1997) Intracellular ATP levels determine cell death fate by apoptosis or necrosis. Cancer Res. 57: 1835-1840

31. Sasaki Y, Fukushima N, Yoshida A and Ueda H (1998) Low-density induced apoptosis of cortical neurons is inhibited by serum factors. Cell. Mol. Neurobiol. 18: $487-496$

32. Ueda H, Fukushima N, Yoshida A, Mizuno K and Hamabe W (2000) Neuronal death inhibitor and its signal transduction. Front. Mech. Mem. Dementia. 83-86

33. Grewal SS, York RD and Stork PJ (1999) Extracellular-signal-regulated kinase signalling in neurons. Curr. Opin. Neurobiol. 9: 544-553

34. Nozaki K, Nishimura M and Hashimoto N (2001) Mitogen-activated protein kinases and cerebral ischemia. Mol. Neurobiol. 23: 1-19

35. Braiman L, Alt A, Kuroki T, Ohba M, Bak A, Tennenbaum T and Sampson SR (2001) Activation of protein kinase $C$ zeta induces serine phosphorylation of VAMP2 in the GLUT4 compartment and increases glucose transport in skeletal muscle. Mol. Cell. Biol. 21: 7852-7861

36. Khayat ZA, Tsakiridis T, Ueyama A, Somwar R, Ebina Y and Klip A (1998) Rapid stimulation of glucose transport by mitochondrial uncoupling depends in part on cytosolic $\mathrm{Ca}^{2+}$ and cPKC. Am. J. Physiol. 275: C1487-1497

37. Kotani K, Ogawa W, Matsumoto M, Kitamura T, Sakaue H, Hino Y, Miyake K, Sano W, Akimoto K, Ohno S and Kasuga M (1998) Requirement of atypical protein kinase Clambda for insulin stimulation of glucose uptake but not for Akt activation in 3T3-L1 adipocytes. Mol. Cell. Biol. 18: 6971-6982

38. Standaert ML, Bandyopadhyay G, Perez L, Price D, Galloway L, Poklepovic A, Sajan MP, Cenni V, Sirri A, Moscat J, Toker A and Farese RV (1999) Insulin activates protein kinases $\mathrm{C}$-zeta and C-lambda by an autophosphorylationdependent mechanism and stimulates their translocation to GLUT4 vesicles and other membrane fractions in rat adipocytes. J. Biol. Chem. 274: 2530825316

39. Hamabe W, Fujita R, Yasusa T, Yoneda F, Yoshida A and Ueda H (2000) (-)1(Benzofuran-2-yl)-2-propylaminopentane shows survival effect on cortical neurons under serum-free condition through sigma receptors. Cell. Mol. Neurobiol. 20: 695-702

40. Ha HC and Snyder SH (1999) Poly(ADP-ribose) polymerase is a mediator of necrotic cell death by ATP depletion. Proc. Natl. Acad. Sci. USA 96: 1397813982

41. Yoshida A, Tokuyama S, Iwamura T and Ueda H (2000) Opioid analgesicinduced apoptosis, caspase-independent cell death in human lung carcinoma A549 cells. Int. J. Mol. Med. 6: 329-335

42. Koivisto UM, Martinez-Valdez H, Bilan PJ, Burdett E, Ramlal T and Klip A (1991) Differential regulation of the GLUT-1 and GLUT-4 glucose transport systems by glucose and insulin in L6 muscle cells in culture. J. Biol. Chem. 266: 2615-2621 